\title{
Cutaneous Squamous Cell Carcinoma of the Head and Neck by AJCC v8 Stage
}

National Cancer Institute

\section{Source}

National Cancer Institute. Cutaneous Squamous Cell Carcinoma of the Head and Neck by A/CC v8 Stage. NCI Thesaurus. Code C133253.

A term that refers to the staging of cutaneous squamous cell carcinoma of the head and neck according to the American Joint Committee on Cancer, 8th edition. 